\title{
DATA ANALYSIS AND LEARNING ANALYTICS FOR MEASURE EFFECTS OF GAMIFICATION IN A MATH ONLINE PROJECT
}

\author{
Ana Paula Lopes, Lurdes Babo, José Azevedo, Cristina Torres \\ Polytechnic of Porto (P. Porto) / ISCAP (PORTUGAL)
}

\begin{abstract}
Nowadays the use of the information and communication technologies (ICT) is more and more common in the learning and teaching process. Modern forms of education have risen and these require the implementation of new learning paradigms: situated cognition, student-centred learning, distributed cognition, constructivism, and communities of practice, among others. However there is an important problem that concerns educators, the lack of student motivation and engagement in education, especially in the e-learning environment (Online Education, Online Courses), where the motivation and the active role of students are definitely the key. Therefore, the interest of researchers in the subject of gamification, which main pillars are motivation, progressiveness and instant feedback, has increased. Furthermore, influence of gamification, depending on utilized components (challenge, curiosity, competion, recognition, etc) may have different effects on students. Thus, there is a need of deeper understanding of dependencies between engagement and implemented gamification elements. The goal of such analysis could be personalization of an e-learning system based on a model that enables management of gamification process individually for every student.
\end{abstract}

The purpose of this paper is to investigate how gamification affects a Mathematics Online Course that is using this model as a pedagogical strategy. It relates such strategy with active learning practices and discusses its effectiveness, investigating how gamification can motivate students to participate more deeply and even to change their self-concept as learners. Moreover, the learning analytics and data analysis shows that implementation of the gamification components contributes to the engagement of students in an e-learning environment, having a positive impact on the final grade.

Keywords: Learning analytics, e-Learning, Moodle, Student Engagement, Gamification.

\section{INTRODUCTION}

In the past few years the widespread use of technologies, such as the Internet, Social Networks and Mobile Phones, affected the education process at Higher Education Institutions (HEI). Nowadays, technology has an important role on education, making possible a better communication and the implementation of the most recent information systems, useful for learning and teaching [1]. But, in general, the lack of motivation and engagement by students in education, especially in e-learning environment, is being a problem. According to [2], when the challenge is appropriate to our abilities we are in the state we call flow, but when it is too hard for our abilities, we get into anxiety; on the contrary if the challenge is too easy for our abilities, we get bored. A way to overcome anxiety is improving our skills, and to overcome monotony is to face more difficult challenges. So, the best should be positioned students in their flow state, and step by step, as long as their skills increase, the difficulty level of challenges should grow. With the purpose of get bigger motivation, learning by doing should be incorporated in the learning methods, it means that we should give to students interesting tasks and provides opportunities to collaborate and interact. Therefore, this makes the task based instruction a particularly significant approach ([3], [4]).

In order to solve the lack of student's motivation problem, several studies have been proposed about how gamification can contribute to this field, taking into account that the influence of gamification, depending on used components (points, levels, etc.), may have different effects on different students. As a result, recently there has been a progressively more interest of researchers in the subject of gamification with the goal of increasing student engagement and motivation ([5], [6], [7]). There has also been an increase in the number of publications presenting results of gamification experiments in educational environments ([4], [5], [6], [7], [8], [21]) contributing to the understanding about the influence of gamification on the level of the engagement and motivation of participants of the educational process. Engagement may be explained by an involvement, enthusiasm to participate in activities or individual attention, which results from a set of different interactions namely, concerning students, lecturers and contents ([9], [10]). The concept of student engagement in educational context 
can also be seen as a real predictor of course success. In their research, [11] found a connection concerning student activity in e-learning environment and course outcome. For that reason, specific analysis of student engagement is essential in order to more accurately predict and increase students' success in online courses. One of the first studies on the use of data from the Learning Management System to analyze student engagement was done by [9], where from the course data they created indicators of student involvement, for instance: average of the number of pages viewed during a visit on website or average time spent on the website. But, there is a diversity of engagement indicators of students, such as: Autonomy, Execution, Participation, Delivery, Fun, etc., which can be found in several studies. These indicators are similar to a measure that indicates the level of engagement of the students.

All over the world, many students struggle when it comes to learning mathematics. Researchers and instructors all around the world suggest different methods, technics and models to learn mathematics [12]. Having some background experience, given by the participation on some Mathematics Projects developed at P.Porto, namelly:

- MatActiva Project - an Online Mathematics Education Project which aims to support and enhance mathematics education, a kind of personalized learning platform in which students can learn at their own pace several Math subjects ([13], [14], [15]);

- Math Without STRESS (M100S) Project - a Massive Open Online Courses (MOOC), which consists of two different Courses, Probability and Combinatorics and Introduction to Differential Calculus ([16], [17]);

- Math Gamification Project (MG) - a Flipped Classroom Project ([18], [19]) with gamification techniques to strengthen and improve the way Mathematics learning and teaching contents, strategies and approaches are achieved in Higher Education (HE).

The purpose of this paper is to investigate how gamification techniques affect a Mathematics Online Course supported by this model as a pedagogical strategy. Some indicators based on course data will be used to measure the effect of the implementation of gamification elements. In section 2, we introduce some concepts about gamification in education and e-learning. The learning environment is described in section 3 and the methodology in section 4 . The results and main conclusions are presented in section 5 and 6 , respectively.

\section{GAMIFICATION IN EDUCATION AND E-LEARNING}

Gamification in education is the concept of applying game principles and mechanics in non-gaming activities, mainly in education. Continuing opportunities for student improvement, huge quantities of feedbacks, tasks too difficult for any one individual to solve alone, and environments that change in response to learners' actions may be offered by well-conceived educational games [20]. We can found in literature and in practice quite a lot of attempts for introducing gamification into b-learning and elearning ([21], [22]), however research about this is still in its early stages [23]. Education is one of the fields where gamification will become a radical technologic shift, principally in e-Learning and lifelong learning.

In opinion of [24], gamification is a strategy that will have a growing interest in education in the coming years.

But, if we pretend to create engaging experiences through game features on non-game context, it is necessary to look at the functioning of game mechanics and dynamics. Game mechanics and dynamics are two important tools related to gamification [25]. According to [26], game mechanics are built by tools, techniques and widgets used to gamify a website or application, when using them individually or collectively, it is possible to stimulate motivational aspects of users. In [26] point of view, the most common game mechanics are:

- Points - Used to reward learners through many dimensions and diverse categories, they can be used to manage different behaviors inside a website or application. When points should stimulate a competition they should be used as scores; on the contrary, when the goal is to provide constant feedback to the user, each individual progress should not be shown to other people [27]. Points can also be used to stimulate the participation of users. 
- Levels - Show the user accomplished a goal. The higher the level, the greater is the respect and status. Levels are frequently defined as threshold points, in a way users can automatically level up based on their participation.

- Challenges, Trophies, Badges/Medals and Accomplishments - Challenges symbolize missions for people to accomplish and then give rewards for the performance. Trophies, badges or medals are the visible acknowledgment that the user has reached new levels and concluded challenges. The essential mechanism to make efficient challenges and levels is to provide users a place where they can show their accomplishments, such as a trophy shelf. Sometimes, the main rewards are fun and interest while seeking goals. When the progress to reach a goal is presented to the user, the following badge is more efficient [28]

- Virtual Goods - Non-physical and unreal objects that may be bought using points collected over time by the users. Virtual goods are a proper way to encourage them to get more points; moreover they offer the possibility of personalizing something that will reflect their identity. According to [29], virtual goods can also be converted into points, badges/medals, discounts and credits. It is very frequent to use virtual coins in different situations including the trade mechanism to buy items and points to increase importance and status.

- Classification Table, Ranking, Score Table - Show the position of users compared to others. Those are tables commonly used to manage and display the user's scores with the objective of using the competition as an incentive to the behavior. According to [27], the main benefit of implementing a classification table is the fact it provides contextual information on the progress of users that could have a motivating effect.

According to Higher Education Funding Council of England, E-learning can be defined as information and communication technologies used to support students to improve their learning [30]. As stated by [31], E-learning platforms and web-based applications are well known, allowing users to access information directly via internet. E-learning has the advantage of being able to learn anywhere and at any time. There is an essential precondition for the reliable implementation of e-learning, which is the administration of e-learning and that requires knowledge of technology and people, whichever can be easily performed using Learning Management Systems (LMS). LMS are at the front position of the online technologies making a good and serious impression on patterns of learning and teaching in HE. LMS, also usually mentioned to as course management systems (CMS) and virtual learning environments (VLE), are becoming omnipresent at HEI around the world, adding a virtual dimension even to the most traditional institutions [32]. In a very short time they have become the most commonly used educational technology in higher education, only ranking behind the Internet and common office applications. These are being used for offering online or technology-enhanced classes and they influence pedagogy, and consequently engagement, by presenting default formats that are designed to guide instructors toward creating courses in certain ways [33].

The NMC Horizon Report: 2013 Higher Education Edition, proposes the additional improvement of learning analytics. Using the results of information platforms that feed data systems analysis will allow to adapt the educational gamified proposal to students' special needs and pace in learning.

Nowadays, Moodle is perhaps the most used open source LMS. Many HEI provide their lecturers with this tool. Moodle is free and allows instructors to create online courses with online multimedia, and maybe that's why is immensely popular among instructors. On the other hand, there is a large Moodle support community that tries to allow instructors to follow new trends in education, as is the case with gamification.

The following part of the paper presents a model of e-learning, using M100S Project in Moodle Platform, which includes gamification, and is designed to be used in higher education. It describes the main elements of the model, how the model works and its impact on students. Therefore, if we can apply gamification on Moodle and it is widely used, it means that Moodle will allow millions of instructors around the world to use gamification in their courses for free.

\section{LEARNING ENVIRONMENT}

The Polytechnic of Porto (Politécnico do Porto), also known as P.Porto, is a Portuguese Higher Education institution providing undergraduate and graduate studies. With more than 20000 students, teachers and researchers has a solid history of online education and innovation through the use of technology. The definition of strategies related to new ways of teaching and learning has been a 
constant concern inside our school, in particular in the long-distance learning domain, either through e-Learning or b-Learning and, recently, through "open-Learning", with the creation of several MOOC in the last four years. "Mathematics without STRESS" (or in its original version - in Portuguese Matemática 100 STRESS - M100S) was the first MOOC launched by P.Porto, for incoming HE students to prepare them for post-high-school courses using mathematics. This MOOC consists of three different Courses: Probability and Combinatorics, Introduction to Differential Calculus and Trigonometry and Complex Numbers. All these courses are created using the same guidelines based on the following division:

- Information Spot

- Math Diagnostic Test (MDT) - entry test, not mandatory;

- Modular subject division with two distinct subsections:

- Video-lectures

- Sequential mini-quizzes;

- "Doubt Ed" - Open Discussion forum;

- Final "Assessment Test"

- Global Course evaluation

- Certificate of attendance

The first course - Probability and Combinatorics (PC) - consists of nineteen different modules/lessons, with 19 randomized quizzes and 24 video-lectures, distributed by the following topics:

- Random Experiment and Sample Space

- Probability and Properties of Probability

- Conditional Probability

- Law of Total Probability and Bayes Theorem

- Fundamental Counting Principle

- Arrangement without repetition

- Permutations

- Pascal's Triangle

- Probability Distribution

- Normal Model.
- Events and Operations on Events

- Exclusive Events

- Intersection Events

- Independent Events

- Factorial of a Natural Number

- Arrangement with repetition

- Combinations

- Newton's Binomial Formula

- Binomial Model

The main page of the PC and IDC courses is presented in Fig. 1.
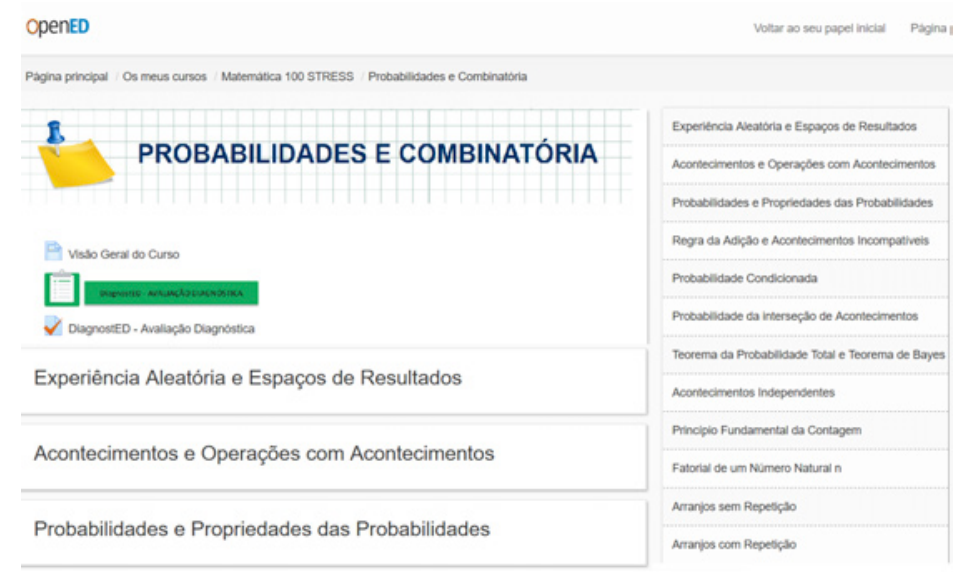

Figure 1 - PC Course main page screenshot

OpenED is an online platform that allows monitoring data, validating and rewards welfare using Gamification. This platform allows instructors to set objectives and monitor all students' activities. 
Because it works directed to goals, students are rewarded with badges and points according to their achievements, which allows instructors gamify their classes. This platform includes tools to gamify a course, but setting course is more than setting badges or conditions, it is necessary a plan for the students.

The features we have for our online course using gamification are:

- Progressive learning: adapted levels

- Social: share activities, comments between teachers or students, social use

- Instant feedback: remarks, suggestions, hints, full solution for each question

- Rewards: points, badges, leaderboards, certificates

Moodle provides tools to deal with these features [34]:

- Viewing conditions resources: restrict access - It allows activities to be hidden until some requirements are accomplished:

- Activity completion: require students to complete (or not) another activity, even with a pass grade

- Date: prevent access until or from a specified date and time

- Grade: require students to achieve a specified grade

- User profile: set conditions depending on the language or country, etc.

- Conditions to activity completion - The combination of conditions to restrict access to an activity and the condition to activity completion builds a strong system to create several learning levels and implement scaffolding in education.

- It shows a completion tick box to show if the activity is completed or not. It is also available for students to manually check the activity (in case teachers allow it).

- Badges and labels - Labels and badges can be used, to inform about achievement. Badges should be used to celebrate big achievements and progress. When adding badges to the course, Moodle allows teachers to set criteria, an activity completion rules as well as a message to inform the student why he or she got the badge.

- Grade book - Are the tools that Moodle has in order to show grades to students, so grade books are the best way that students have in Moodle to track their progress. Teachers can edit grade settings and allow students to show their rank, which is the position in relation to the rest of the class (similar to a leaderboard in terms of gamification) or the percentage value of each item (similar to a progress bar).

- Activities: quizzes, assignment, workshops and lessons - This activity allows teachers to build quizzes with several types of questions: multiple choice, true-false, short-answer questions and others. When setting the quiz, Moodle lets us choose between different types of feedback either in general, in the particular question or in the answer given. The feedback system allows teacher to set a great number of possibilities. Quizzes have a grade, which is available for students in the grade book.

The assignment activity allows teacher to collect work from students (files), review it and provide feedback in terms of grades and comments.

The workshops activity allows students to grade other students or carry out self-assessment. They will get two marks: one for the work they sent and the other one for their assessment of the peers' work. Therefore, teachers assess the work and the way students assess. Workshops, in terms of peer assessment, increase student responsibility and autonomy and provide more relevant feedback to students given by other students. Both grades are available in the grade book.

The lessons activity is the best way to add several learning paths before Moodle 2.0. However, conditions are stronger than lessons, so from Moodle 2.0 on, conditions took the lead creating several learning paths in Moodle.

- Other activities: surveys, choices, forums and chats - These are activities that allow students' interaction, it means that, forum and chat allow students to socialize in the course. Teachers 
can also answer questions that students ask in forums. Surveys and choices provide an ungraded feedback from students to teachers.

- Course Activity Report - A course activity report, showing the number of views for each activity and resource (and any related blog entries), can be viewed by managers, teachers and nonediting teachers

Therefore, professors can build a set of activities for students to perform and for those that complete the proposed tasks proposed by the professor are awarded with points and badges as recognition of their work. OpenED is also an online reward platform on student behavior, since this seeks to stimulate specific positive behavior like perseverance, curiosity and teamwork, encouraging the construction of a good character in students.

\section{METHODOLOGY}

In this study different techniques from exploratory qualitative research and quantitative methods were used for the data collection. At the beginning of the academic year, an achievement paper test was administrated to all the students and this was given again as part of a final test. The test, scored between 0 and 20, was composed of 6 multiple choice questions and 3 groups of open-ended questions, all questions were carefully chosen and based upon material to be covered in the course. We analyzed the individual class changes in achievement from the pretest to the posttest and the differences in the tests grades between the two groups.

The study with a total of 47 students who were attending to Mathematics Zero (MZ) subject from Zero Year Course in ISCAP, aged 18 and 20 years old, was divided into experimental and control groups. The composition of the experimental group was 15 ( 9 male and 6 females) and control group was 32 (18 male and 14 females). To the experimental group, with 15 students was taught Probability and Combinatorics using Gamification in a flipped classroom method, while the control group, with 32 students was taught by traditional teaching methods, sometimes using the M100S without Gamification for doing some homework.

The research was developed on the subject of Probability and Combinatorics and was conducted with a gamification learning approach, where the OpenED platform was used as a tool for sharing course contents (resources, assignments), as a communication tool and as a gradebook.

The purpose of this study was to implement gamification components (points and ranking) into a MOOC and investigate how gamification affects a Mathematics Online Course that is using this model as a pedagogical strategy by analyzing the effect of this implementation on students' engagement and in their grades.

We started by identify which activities would be gamified in M100S and how. As we have referred, we chose for this study the subject Probability and Combinatorics, which objectives were based on the pedagogical project of the Mathematics Zero Course and tried to fill the needs of this project. In the Mathematics without STRESS MOOC hundreds of questions about PC issue were created. All of these with feedback, allowing the students to see a suggested solution, step by step (Fig. 2). Therefore, with a huge Pool of Questions, we could randomly generate thousands of different homework, assignments and tests, since we have categorized learning items (modules) separately and each section has four subsections, namely: Easy, Medium, Difficult and National Tests/Exams (Fig. 3). So, students could be provided with a huge number of unique practice problems that represent any question that they would meet in the course. For this reason, we consider M100S as an interactive learning environment for mathematical gamification. Hence, this interactive mathematical environment to generate and grade a huge number of questions has great potential for gamification, because it easily allows students to keep practicing a kind of questions until they meet their desired level of achievement. On each of the 19 topics existing in the Probability and Combinatorics Course, students were allowed an unlimited number of attempts at each set of exercises, always with full solution presented after each question was answered so they were able to practice as much as they want before taking the online Quizz on the topic studied where students only had an attempt to do it. 


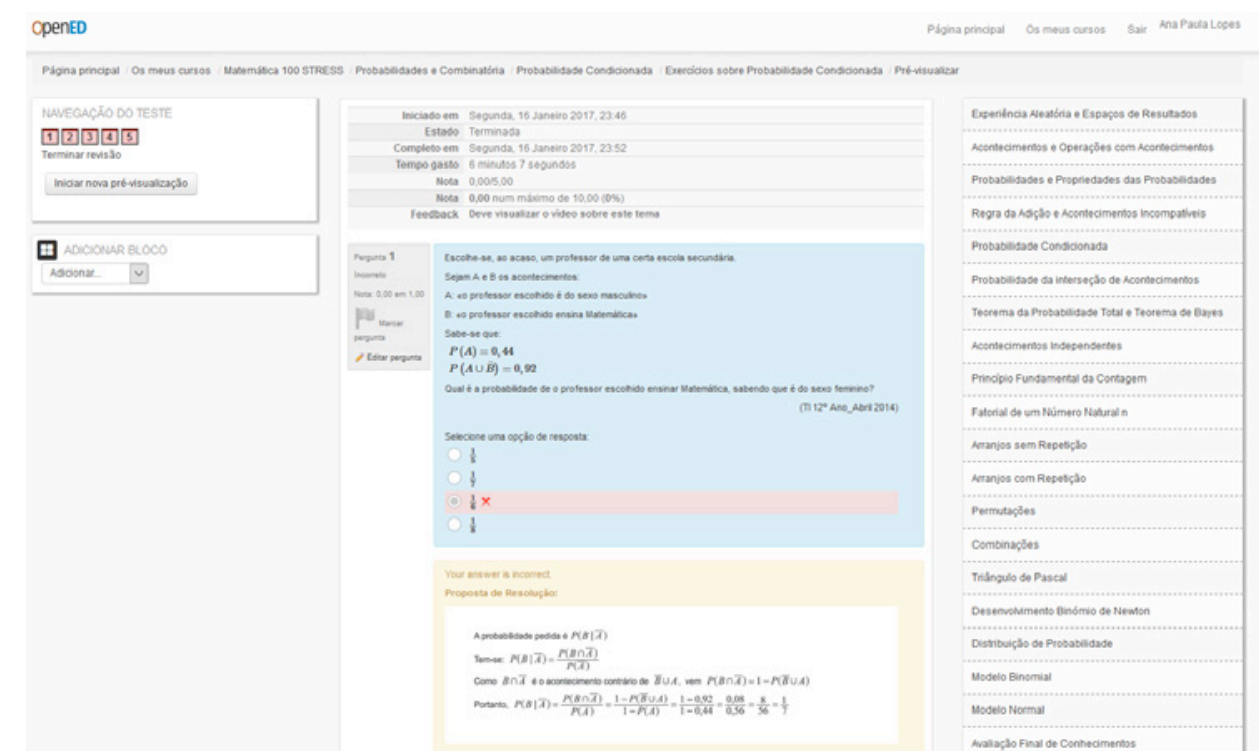

Figure 2 - Screenshot of a Conditional Probability exercise with a full suggested solution, step by step, in the interactive environment M100S

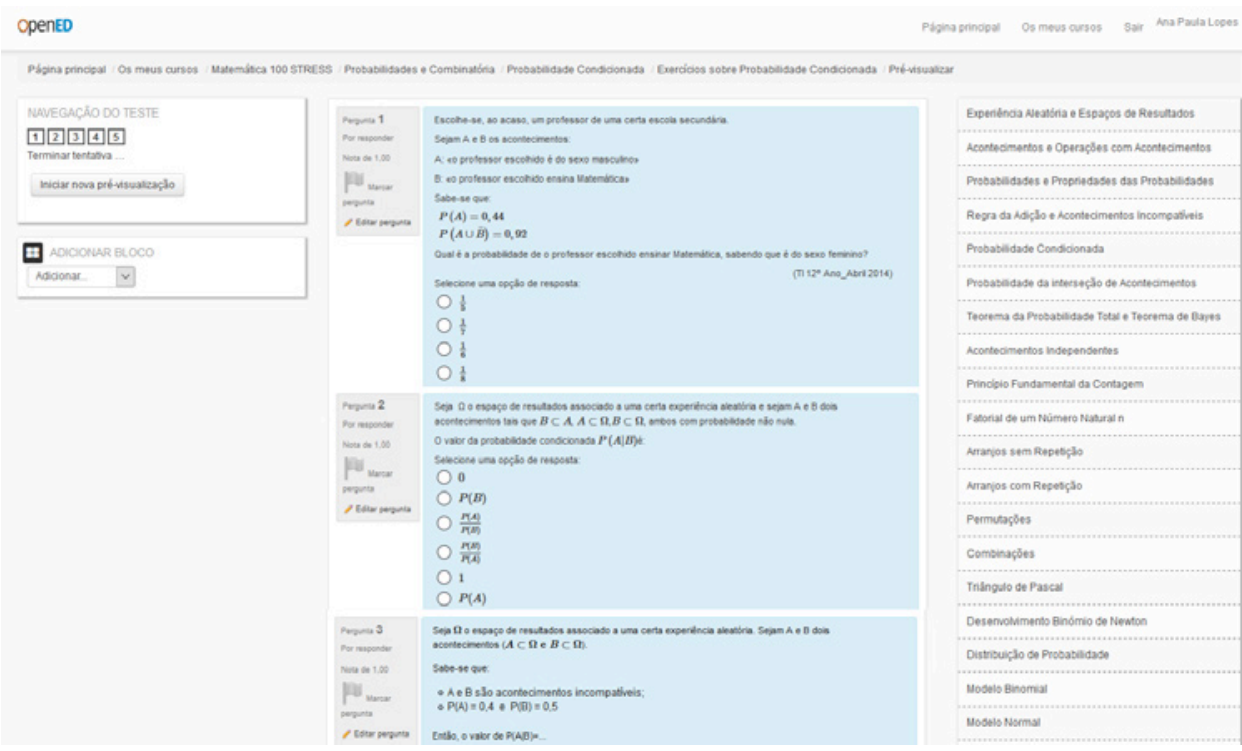

Figure 3 - Screenshot of a randomly Conditional Probability set of exercises in the interactive environment M100S

In order to keep students motivated and engaged to continue using this Gamified Flipped model until their desired level of achievement be reached, we created a structure that encourage students to modify their goals upwards as they achieve the results they wanted. It means, that, when an assignment is completed, students are rewarded with badges and extra points according to their achievements, which allows students who are willing to continue to practice reach higher levels where more difficult and challenging questions are found. This is very useful for guiding and encouraging persistence of students when they face challenging or difficult questions rather they use a textbook practice questions and do assignments alone.

\section{RESULTS}

Based in our methodology we performed some analysis from Moodle data. For the group of students $(n=15)$ that attended to the course we have several results.

The number of available activity data generated by students during the course was 2784 . Resources within the course have been divided into the following main categories: 
- Random Experiment and Sample Space (172 views)

- Events and Operations on Events (138 views)

- Probability and Properties of Probability (136 views)

- Exclusive Events (138 views)

- Conditional Probability (237 views)

- Intersection Events (115 views)

- Law of Total Probability and Bayes Theorem (111 views)

- Independent Events (120 views)

- Fundamental Counting Principle (124 views)

- Factorial of a Natural Number (128 views)

- Arrangement without repetition (243 views)

- Arrangement with repetition (155 views)

- Permutations (132 views)

- Combinations (362 views)

- Pascal's Triangle (125 views)

- Newton's Binomial Formula (223 views)

- Probability Distribution (121 views)

- Binomial Model (232 views)

- Normal Model (235 views)

Remaining types of course actions (surveys, questionnaires, forum, blog, other course resources, like for instance, Video-Lectures) were not taken separately into consideration in this analysis. However, they have been included into an overall summary analysis of all course actions.

A Survey was administrated during the last week of classes. The questions were based in the reliability tests by UMASS's research team - The SimCalc Research team of the Kaput Center, University of Massachusetts Dartmouth - about Measuring Student Attitude in Mathematics Classrooms [35]. We used a 5 point Likert scale, "1" represented Very Unlikely and "5" represented Very Likely, to maintain stability given the intuitive understanding and insight of attitude concerning certain activities measured by several items. To the students from experimental group, four 1-5 Likert scale questions were still asked on the final survey, whether they would prefer a Gamified Flipped Math class over a traditional math class. In this survey we also collected qualitative comments, several of which suggested that students found that they had enjoyed and learned more from the M100S. In particular, students really liked of the instant feedback of having a suggestion of solution provided after each question, which helped them gain solid knowledge and skills in Math. From the comments of students most found the online assignments challenging and engaging.

An analysis was performed on both the pre $M Z$ course and post $M Z$ course assessment, as well as whether the Gamification Flipped model influenced student achievement, which shows that the implementation of this model contributed to the engagement of students, having a positive impact on the final grade.

\section{CONCLUSION}

The purpose of this study was investigate how gamification affects a Mathematics Online Course that was using Gamification model as a pedagogical strategy and also to examine whether different instructional practices, specifically Mathematics Zero Gamification in a Flipped Classroom environment with the use of OpenED platform and M100S MOOC versus MZ Traditional Classroom, influenced students' achievement and perceptions of learning in Mathematics. The gamification model for online assignments was described, as well as its implementation in MZ course.

We know that solving mathematical problems demands knowledge, skills, creativity and persistence. To help students in this process, we proposed a model that associates play, learning, motivation, participation and engagement. Motivation and engagement are the most important elements of learning. Keeping students motivated and engaged is imperative for successful online education. 
In OpenED platform, students have at their disposal a set of assignments on each of the 19 topics existing in the Probability and Combinatorics Course. In these assignments, students were allowed to do an unlimited number of attempts at randomized groups of challenging questions, always with a full solution provided after each question. On the contrary, in the online Quizz on the topic studied where students only had an attempt to do it.

The students' reaction was positive to these assignments as at the same time were more motivated and satisfied with their individual learning outcomes. The results show that there was a positive impact in the scores of gamification flipped course.

Future research regarding implementation of gamification elements in e-learning environments is still needed in order to increase understanding of its influence on students' engagement, motivation and achievements.

\section{REFERENCES}

[1] Bedrule-Grigoruta, M. V., \& Rusua, M. L. (2014). Considerations about E-Learning Tools for Adult Education. Procedia - Social and Behavioral Sciences, 142, 749-754.

[2] Csikszentmihalyi, M. (1990). Flow. The Pshychology of Optimal Experience. Harper \& Row.

[3] Markham, T., Larmer, J., and Ravitz, J. (2003). Project Based Learning Handbook: A Guide to Standards-Focused Project Based Learning for Middle and High School Teachers. Buck Inst for Education; 2nd Rev Spl edition.

[4] Villagrá, C. J., Gallego, F. J., Molina, R., and Llorens, F. (2014). "ABPgame+: siete asignaturas, un proyecto". Actas de las XX Jornadas sobre la Enseñanza Universitaria de la Informática (JENUI 2014).

[5] Fitz-Walter, Z., Tjondronegoro, D., \&Wyeth, P. (2012, November). A gamified mobile application for engaging new students at university orientation. In Proceedings of the 24th Australian Computer-Human Interaction Conference (pp. 138e141), ACM.

[6] Kapp, K. M. (2012). The gamification of learning and instruction: Game-based methods and strategies for training and education. John Wiley \& Sons.

[7] Dicheva D., Dichev C., Agre G. \& Angelova G. (2015). Gamification in Education: A Systematic Mapping Study. Educational Technology \& Society, 18 (1).

[8] Pankiewicz, M. (2015). Gamifikacja - tymczasowy trend czy długofalowa strategia? Zarządzanie Zasobami Ludzkimi, 2(103), 123-132.

[9] Beer, C., Clark, K., Jones, D. (2010). Indicators of engagement. Curriculum, technology \& transformation for an unknown future. Proceedings ascilite Sydney, 75-86.

[10] Richards, G. (2011). Measuring engagement: Learning analytics in online learning. Electronic Kazan 2011.

[11] Smith, V. C., Lange, A., \& Huston, D. R. (2012). Predictive Modeling to Forecast Student Outcomes and Drive Effective Interventions in Online Community College Courses. Journal of Asynchronous Learning Networks, 16(3), 51-61.

[12] Stanislav, V. (2013). Online Problems for Mathematics and Computer Science Education. Retrieved from http://is.muni.cz/th/373843/fi_b/thesis.pdf

[13] Lopes, A., Babo, L., Azevedo, J. (2008). Teaching and Learning Mathematics Using Moodle. INTED2008 Abstracts Book ISBN: 978-84-612-0192-1 and INTED2008 CD Proceedings ISBN: 978-84-612-0190-7.

[14] Torres, C., Lopes, A., Babo, L., Azevedo, J. (2009). Developing Multiple-Choice Questions in Mathematics. ICERI 2009 - International Conference of Education, Research and Innovation, Proceedings CD ISBN: 978-84-613-2955-7, Abstracts CD ISBN: 978-84-613-2953-3.

[15] Babo, L., Azevedo, J., Torres, C., Lopes, A. (2010). New Challenges in Mathematics for the European Higher Education. In proceedings of ICERI 2010, International Conference of Education, Research and Innovation, Proceedings CD ISBN: 978-84-614-2439-9, Abstracts CD ISBN: 978-84-614-2438-2. 
[16] Soares, F., Lopes, A. P., (2016). "Teaching Mathematics Using Massive Open Online Courses". In 10th International Technology, Education and Development Conference - INTED2016 Proceedings, $7^{\text {th }}-9^{\text {th }}$ March 2016, Valencia, Spain, Pages: 2635-2641, ISBN: 978-84-608-56177, ISSN: 2340-1079, doi: 10.21125/inted.2016.1563

[17] Lopes, A. P., Soares, F., (2016). "The Development and Implementation of Math Project in a Hei - Expectations, Objectives, Experiences and Analysis". In 10th International Technology, Education and Development Conference - INTED2016 Proceedings, $7^{\text {th }}-9^{\text {th }}$ March 2016, Valencia, Spain, Pages: 6522-6530, ISBN: 978-84-608-5617-7, ISSN: 2340-1079, doi: 10.21125/inted.2016.0540

[18] Lopes, A. P., Soares, F., (2016). "Flipping a Financial Mathematics Course in a Higher Education Institution (Hei)". Proceedings of 10th International Technology, Education and Development Conference - ICERI2016, 14th-16th November 2016, Seville, Spain, Pages: 36343641, ISBN: 978-84-617-5895-1, ISSN: 2340-1095. doi: 10.21125/iceri.2016.1860

[19] Lopes, A. P., Soares, F., (2016). "Video Lectures and Online Activities to Engage Students in a Flipped Classroom". In 8th Annual International Conference on Education and New Learning Technologies EDULEARN16 Proceedings, Barcelona (Spain) on the 4th, 5th and 6th of July, 2016. Pages: 8688-8695, ISBN: 978-84-608-8860-4, ISSN: 2340-1117, doi: 10.21125/edulearn.2016.0890

[20] Barab, S. A., Gresalfi, M., \& Ingram-Goble, A. (2010). Transformational play using games to position person, content, and context. Educational Researcher, 39(7), 525-536.

[21] Muntean, C. I. (2011). Raising engagement in e-learning through gamification. The 6th International Conference on Virtual Learning ICVL 2012, Romania, 323-329.

[22] Hickey, D. T., \& Rehak, A. (2013). Wikifolios and participatory assessment for engagement, understanding, and achievement in online courses. Journal of Educational Media and Hypermedia, 22(4), 407-441.

[23] Filsecker, M., \& Hickey D. T. (2014). A multilevel analysis of the effects of external rewards on elementary students' motivation, engagement and learning in an educational game. Computers \& Education, 75, 136-148.

[24] Johnson, L., Adams Becker, S., Cummins, M., Estrada, V., Freeman, A., and Ludgate, H. (2013). NMC Horizon Report: 2013 Higher Education Edition. The New Media Consortium.

[25] Law, F. L., Kasirun, Z. M., \& Gan, C. K. (2011, December). Gamification towards sustainable mobile application. In Software Engineering (MySEC), $20115^{\text {th }}$ Malaysian Conference, 349353). IEEE.

[26] Bunchball, I. (2010). Gamification 101: An introduction to the use of game dynamics to influence behavior. White paper.

[27] Werbach, K., \& Hunter, D. (2012). For the win: How game thinking can revolutionize your business. Wharton Digital Press.

[28] Antin, J., \& Churchill, E. F. (2011). Badges in social media: A social psychological perspective. In CHI 2011. Vancouver, BC: ACM.

[29] McHale, R. (2012). Navigating social media legal risks: Safeguarding your business. Pearson Education, Inc.. Web ISBN-13: 978-0-13-303365-6.

[30] Higher Education Funding Council of England. (2005). HEFCE strategy for e-learning. Retrieved from http://www.hefce.ac.uk/pubs/hefce/2005/05_12/

[31] Zamfiroiu, A., \& Sbora, C. (2014). Statistical analysis of the behavior for mobile E-learning. Procedia Economics and Finance, 10, 237-243.

[32] Coates, H., James, R., \& Baldwin, G. (2005). A critical examination of the effects of learning management systems on university teaching and learning. Tertiary education and management, 11(2005), 19-36.

[33] Lane, L. M. (2009). Insidious Pedagogy: How course management systems affect teaching. 14(10). Retrieved from http://firstmonday.org/htbin/cgiwrap/bin/ojs/index.php/fm/article/view/2530/2303 
[34] Moodle Docs, Managing a Moodle Course. Retrieved from https://docs.moodle.org/23/en/Activity_completion_settings

[35] Brookstein, A., Hegedus, S., Dalton, S., Tapper, J. and Moniz, R. (2011). Measuring Student Attitude in Mathematics Classrooms. University of Massachusetts Dartmouth. Retrieved from http://www.kaputcenter.umassd.edu/downloads/products/technical_reports/tr4_student_attitude. pdf 